\title{
Severe Chronic Allergic (and Related) Diseases: A Uniform Approach - A MeDALL - GA2LEN - ARIA Position Paper
}

\author{
Bousquet, J ; et al
}

\begin{abstract}
Concepts of disease severity, activity, control and responsiveness to treatment are linked but different. Severity refers to the loss of function of the organs induced by the disease process or to the occurrence of severe acute exacerbations. Severity may vary over time and needs regular follow-up. Control is the degree to which therapy goals are currently met. These concepts have evolved over time for asthma in guidelines, task forces or consensus meetings. The aim of this paper is to generalize the approach of the uniform definition of severe asthma presented to WHO for chronic allergic and associated diseases (rhinitis, chronic rhinosinusitis, chronic urticaria and atopic dermatitis) in order to have a uniform definition of severity, control and risk, usable in most situations. It is based on the appropriate diagnosis, availability and accessibility of treatments, treatment responsiveness and associated factors such as comorbidities and risk factors. This uniform definition will allow a better definition of the phenotypes of severe allergic (and related) diseases for clinical practice, research (including epidemiology), public health purposes, education and the discovery of novel therapies
\end{abstract}

DOI: https://doi.org/10.1159/000332924

Posted at the Zurich Open Repository and Archive, University of Zurich

ZORA URL: https://www.zora.uzh.ch/63345

Journal Article

Published Version

Originally published at:

Bousquet, J; et al (2012). Severe Chronic Allergic (and Related) Diseases: A Uniform Approach A MeDALL - GA2LEN - ARIA Position Paper. International Archives of Allergy and Immunology, 158(3):216-231.

DOI: https://doi.org/10.1159/000332924 


\section{Severe Chronic Allergic (and Related) Diseases: A Uniform Approach - A MeDALL - GA²LEN - ARIA Position Paper}

In collaboration with the WHO Collaborating Center for Asthma and Rhinitis

J. Bousquet ${ }^{a-e, 1,2} \quad$ J.M. Anto a, b, 3-6 $\quad$ P. Demolya, c, d, 7,8 $\quad$ H.J.Schünemann ${ }^{a, c, 9} \quad$ A. Togias $^{10}$ M. Akdis ${ }^{a, b}, 11$

C. Auffray $^{b, 12}$ C. Bachert ${ }^{a-c, 13}$ T. Biebera, 14 P.J. Bousquet ${ }^{a, c, d, 1}$ K.H.Carlsen ${ }^{a-c, 15}$ T.B.Casale ${ }^{c, 16}$ A.A.Cruz ${ }^{c, 17}$

T. Keil ${ }^{a, b}, 18$ K.C. Lodrup Carlsen ${ }^{\mathrm{a}-\mathrm{c}, 15}$ M. Maurer ${ }^{\mathrm{a}-\mathrm{c}, 19}$ K. Ohta ${ }^{c, 20}$ N.G. Papadopoulos ${ }^{\mathrm{a}, \mathrm{c}, 21}$ M. Roman Rodriguez ${ }^{22}$

B. Samolinskic, 23 I. Agache ${ }^{c, 24}$ A. Andrianarisoa ${ }^{e, 25}$ C.S. Ange, $36 \quad$ I. Annesi-Maesano ${ }^{a-c, 26}$

F. Ballester ${ }^{5,27}$ C.E. Baena-Cagnanic, 28,29 X. Basagaña ${ }^{b, 3-5} \quad$ E.D. Batemanc, 30 E.H. Bela, $31 \quad$ A. Bedbrook ${ }^{\text {a-d, } 7}$

B. Beghéc, 32 M. Bejie, 33 A. Ben Kheder, e, 34 M. Benet ${ }^{b, 3-5}$ K.S. Bennoor ${ }^{b, 35}$ K.C. Bergmannn ${ }^{a, c, 19}$ F. Berrissoule, 36

C. Bindslev Jensen a-c, 37 E.R. Bleecker ${ }^{38}$ S. Bonini ${ }^{a, c, 39}$ A.L. Boner ${ }^{40}$ L.P. Boulet ${ }^{c, e, 41}$ C.E. Brightling ${ }^{42}$ J.L. Brozek ${ }^{c, 9}$

A. Bush ${ }^{43}$ W.W. Busse ${ }^{44}$ P.A.M. Camargos ${ }^{c, 45}$ G.W. Canonicaa, ${ }^{a, 46}$ W. Carrc, 47 A. Cesario ${ }^{48,49}$ Y.Z. Chen ${ }^{c, 50}$

A.M. Chiriac 1 D.J.Costac,51 L. Cox ${ }^{52}$ A. Custovic ${ }^{c, 53}$ R. Dahlc,54 U. Darsow ${ }^{a, 55}$ T. Didie, 55A W.K. Dolen ${ }^{56}$

H. Douaguic, 57 R. Dubakiene ${ }^{b, c, 58}$ A. El-Meziane ${ }^{e, 59}$ J.A. Fonseca ${ }^{c, 60}$ W.J. Fokkens ${ }^{a, c, 61}$ E. Fthenou ${ }^{b, 62}$

A. Gamkrelidzec,63 J.Garcia-Aymerich ${ }^{\text {b, 3-6 }}$ R. Gerth van Wijk, 64 E. Gimeno ${ }^{\text {b, } 3}$ S. Guerra, 3-5,64A T. Haahtelaa-c, 65

H. Haddad ${ }^{e, 66}$ P.W. Hellings ${ }^{c, 67}$ B. Hellquist-Dahl ${ }^{c, 54}$ C. Hohmann ${ }^{a, b}, 18$ P. Howarth ${ }^{a, c, 68}$ J.O. Hourihane ${ }^{69}$

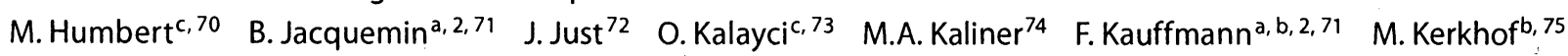

G. Khayate, 76 B. Koffi N'Gorann,e,77 M. Kogevinas ${ }^{b, 3-5,77 A}$ G.H. Koppelman ${ }^{b, 78}$ M.L. Kowalskia-c, 79 I. Kull a, b, 80,81

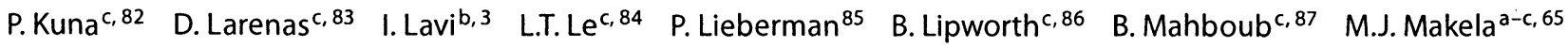

F. Martine, 88 F.D. Martinez ${ }^{b, 89}$ G.D. Marshall 90 A. Mazon ${ }^{\text {e, } 27}$ E. Melen ${ }^{\mathrm{a}, b, 91} \quad$ E.O. Meltzer, ${ }^{c, 92}$ F. Mihaltan ${ }^{c, e, 93}$

Y. Mohammad c,e, 94 A. Mohammadie, 95 I. Momas ${ }^{b, 96}$ M. Morais-Almeidac, 97 J. Mullola, ${ }^{\text {a, }, 98}$ A. Muraro ${ }^{99}$

R. Naclerio ${ }^{c, 100}$ S. Naftie, 101 L. Namazova-Baranovaa,c, 102 M.C. Nawijn ${ }^{b, 103}$ T.D. Nyembue ${ }^{\text {c, } 104}$ S. Oddie ${ }^{\text {b, } 105,106}$

R.E. O'Hehirc, 107 Y. Okamoto ${ }^{108}$ M.P. Orruc, 109 C. Ozdemir, 110 G.S. Ouedraogo ${ }^{c, 111}$ S. Palkonen ${ }^{\text {a-c, } 112}$

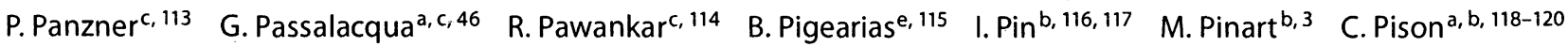

T.A. Popove, 121,122 D. Porta ${ }^{b}, 123$ D.S. Postma ${ }^{b, 124}$ D. Price ${ }^{c, 125}$ K.F. Rabe ${ }^{c, 126}$ J. Ratomaharo, 127 S. Reitamo ${ }^{a, b, 65}$

D. Rezaguie, 128 J. Ringa,c, 129 R. Roberts ${ }^{130}$ J. Rocac, 131 B. Rogala ${ }^{a, c, 132}$ A. Romano ${ }^{a, c, 133}$ J. Rosado-Pintoc, 134

D. Ryan ${ }^{135,136}$ M. Sanchez-Borges ${ }^{c, 137}$ G.K. Scadding ${ }^{c, 138}$ A. Sheikh ${ }^{139}$ F.E.R. Simonsc, 140 V. Siroux ${ }^{\text {b, } 141,142}$ P.D. Schmid-Grendelmeier ${ }^{\mathrm{a}, c, 143}$ H.A. Smit ${ }^{\text {b, } 144}$ T. Sooronbaevc, ${ }^{c} 145$ R.T. Stein ${ }^{3,145 A}$ P.J. Sterk, 31, 127 J. Sunyer ${ }^{c, 3-6}$ I. Terreehorst ${ }^{a, c, 146}$ E. Toskala ${ }^{a-c, 147} \quad$ Y. Tremblay ${ }^{e, 148}$ R. Valenta ${ }^{a, b}, 149$ D. Valeyre ${ }^{e, 150}$ O. Vandenplas ${ }^{c, 151}$

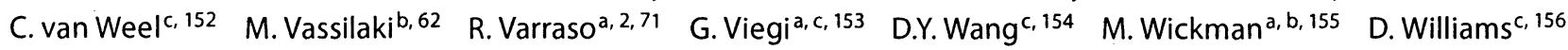
S. Wöhrl ${ }^{a, 157}$ J. Wright ${ }^{\text {a, b, } 105}$ A. Yorganciogluc, 158 O.M. Yusufc, 159 H.J.Zarc, ${ }^{c} 160$ M.E. Zernottic, 28 M. Zidarn ${ }^{161}$ N. Zhong ${ }^{c, 162}$ T. Zuberbier ${ }^{\mathrm{a}-\mathrm{c}, 19,163}$

${ }^{a}$ Member of GA ${ }^{2}$ LEN (Global Allergy and Asthma European Network, Grant Agreement FP6); ${ }^{b}$ Member of MeDALL (Mechanisms of the Development of ALLergy, Grant Agreement FP7 No. 264357, MeDALL paper No. 5); 'Member of ARIA

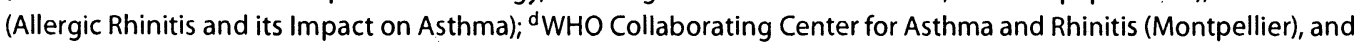
'Espace Francophone de Pneumologie (Société de Pneumologie de Langue Française)

\section{KARGER}

Fax +41613061234 E-Mail karger@karger.ch www.karger.com (c) 2012 S. Karger AG, Basel

1018-2438/12/1583-0216\$38.00/0

Accessible online at: www.karger.com/iaa
Correspondence to: Prof. Jean Bousquet Centre Hospitalier Universitaire, Montpellier FR-34295 Montpellier Cedex 05 (France) Tel. +33611428847

E-Mail jean.bousquet@inserm.fr 
Education, Södersjukhuset, Karolinska Institutet, Stockholm, Sweden;

${ }^{82}$ Barlicki University Hospital, Medical University of Lodz, Lodz,

Poland; ${ }^{83}$ Allergy Department, Hospital Médica Sur, Mexico City, Mexico; ${ }^{84}$ University of Medicine and Pharmacy, Hochiminh City, Vietnam; ${ }^{85}$ University of Tennessee College of Medicine, Memphis Tenn., USA $;{ }^{86}$ Asthma and Allergy Research Group, Univeristy of Dundee, Dundee, UK; ${ }^{87}$ Pulmonary and allergy unit, Dubai Health Authority and University of Sharjah, United Arab Emirates; ${ }^{88}$ Compiègnes, Association Franco-Vietnamienne de Pneumologie;

${ }^{89}$ Arizona Respiratory Center, University of Arizona, Tucson, Ariz., USA;

${ }^{90}$ Division of Clinical Immunology and Allergy, University of Mississippi Medical Center, Jackson, Miss., USA; ${ }^{91}$ Institute of Environmental Medicine, Karolinska Institutet, and Astrid Lindgren Children's Hospital, Karolinska University Hospital, Stockholm, Sweden; ${ }^{92}$ Allergy and Asthma Medical Group ànd Research Center, University of California, San Diego, Calif., USA; ${ }^{33}$ Institute of Pneumology Marius Nasta, Bucharest, Romania; ${ }^{94}$ Department of Internal Medicine, Tishreen University School of Medicine, WHOEMRO CC for CRD, Lattakia, Syria; ${ }^{95}$ Association Franco-Marocaine de Pathologie Thoracique (AFMAPATH), Marrakech, Morocco; ${ }^{96}$ Department of Public health and biostatistics, Paris Descartes University, EA 4064 and Paris Municipal Department of Social Action, Childhood and Health, Paris, France; ${ }^{97}$ Immunoallergy Department, CUF-Descobertas Hospital, Lisbon, Portugal; ${ }^{98}$ Rhinology Unit and Smell Clinic, ENT Department, Hospital Clinic, IDIBAPS, Barcelona, Spain; ${ }^{99}$ Department of Pediatrics, University of Padua, Padua, Italy; ${ }^{100}$ University of Chicago, Chicago, III., USA; ${ }^{101}$ Mustapha Hospital, Algiers, Algeria; ${ }^{102}$ Scientific Center for Children's Health RAMS, Moscow, Russia; ${ }^{103}$ Laboratory of Allergology and Pulmonary Diseases, Department of Pathology and Medical Biology, GRIAC Research Institute, University Medical Center Groningen, University of Groningen, Groningen, The Netherlands; ${ }^{104}$ Kinshasa University, Kinshasa, Congo; ${ }^{105}$ Bradford Institute for Health Research, Bradford Teaching Hospitals Foundation Trust, Bradford, UK; ${ }^{106}$ Bradford Neonatology, Bradford Royal Infirmary, Bradford, UK; ${ }^{107}$ Alfred Hospital and Monash University, Melbourne, Vic., Australia; ${ }^{108}$ Department of Otorhinolaryngology, Chiba University Hospital, Chiba, Japan; ${ }^{109}$ Pharmacist, Italy; ${ }^{110}$ Divison of Pediatric Allergy and Immunology and Memorial Health Group, Marmara University, Istanbul, Turkey; ${ }^{111}$ Centre Hospitalier Universitaire Pédiatrique Charles de Gaulle, Ouagadougou, Burkina Faso; ${ }^{112}$ EFA European Federation of Allergy and Airways Diseases Patients' Associations, Brussels, Belgium; ${ }^{113}$ Department of Immunology and Allergology, Faculty of Medicine in Plzen, Plzen; Charles University, Prague, Czech Republic; ${ }^{114}$ Nippon Medical School, Bunkyo-ku, Tokyo, Japan; ${ }^{115}$ NICE and Société de Pneumologie de Langue Française, Paris, France; ${ }^{116} \mathrm{CHU}$ de Grenoble, Grenoble, France; ${ }^{117}$ Inserm, U823, Institut Albert Bonniot, Grenoble, and University Joseph Fourier, Grenoble, France; ${ }^{118}$ Department of Pulmonology, University Hospital of Grenoble, Grenoble, France; ${ }^{119}$ Inserm 884, Grenoble, France; ${ }^{120}$ University of Grenoble, Grenoble, France; ${ }^{121}$ Clinic of Allergy and Asthma, Medical University Sofia, Sofia, Bulgaria; ${ }^{122}$ Alexander's University Hospital, Sofia, Bulgaria; ${ }^{123}$ Department of Epidemiology, Regional Health Service Lazio Region, Rome, Italy; ${ }^{124}$ Department of Pulmonology, GRIAC Research Institute, University Medical Center Groningen, University of Groningen, Groningen, The Netherlands; ${ }^{125}$ GPIAG, University of Aberdeen, Aberdeen, UK; ${ }^{126}$ Department of Pulmonology, Leiden University Medical Center, Leiden,
The Netherlands; ${ }^{127}$ Hôpital Privé d'Athis-Mons, Site Caron, Service de Pneumologie, Athis-Mons, France; ${ }^{128}$ Association Franco-Algérienne de Pneumologie (AFAP); ${ }^{129}$ Technische Universität München, Munich, Germany; ${ }^{130}$ University of Wisconsin School of Medicine and Public Health, Madison, Wisc., USA; ${ }^{131}$ Institut Clínic del Tòrax, Hospital Clínic, IDIBAPS, CIBERES, Universitat de Barcelona, Barcelona, Spain;

${ }^{132}$ Silesian University School of Medicine, Zabrze, Poland; ${ }^{133}$ Department of Internal Medicine and Geriatrics, UCSC-Allergy Unit, Complesso Integrato Columbus, Rome, Italy; ${ }^{134}$ Immunoallergy Department, Hospital da Luz, and Hospital Dona Estefänia, Lisbon, Portugal; ${ }^{135}$ Woodbrook Medical Centre, Loughborough, UK; ${ }^{136}$ University of Aberdeen, Aberdeen, UK; ${ }^{137}$ Department of Allergy and Clinical Immunology, Centro Medico-Docente La Trinidad, Caracas, Venezuela; ${ }^{138}$ Royal National TNE Hospital, University College London, London, UK; ${ }^{139}$ Centre for Population Health Sciences, Medical School, The University of Edinburgh, Edinburgh, UK; ${ }^{140}$ Faculty of Medicine, University of Manitoba, Winnipeg, Man., Canada; ${ }^{141}$ INSERM, U823, Team of Environmental Epidemiology applied to Reproduction and Respiratory Health, Grenoble, France; ${ }^{142}$ Université Joseph Fourier, Grenoble, France; ${ }^{143}$ Allergy Unit, Department of Dermatology, University Hospital, Zürich, Switzerland; ${ }^{144}$ Julius Center of Health Sciences and Primary Care, University Medical Center Utrecht, University of Utrecht, Utrecht, The Netherlands; ${ }^{145}$ National Centre Cardiology and Internal Medicine, Bishkek, Kyrgyzstan; ${ }^{145 \mathrm{~A}}$ School of Medicine, Pontificia Universidade Católica RGS, Porto Alegre, Brazil; ${ }^{146}$ Department of ENT and Paediatrics, AMC hospital, Amsterdam, The Netherlands; ${ }^{147}$ Finnish Institute of Occupational Health, Helsinki, Finland; ${ }^{148}$ Department of Obstetric and Gynecology, Axis in Reproduction, Perinatal and Child Health, Faculty of Medicine, Laval University, Quebec, Que., Canada; ${ }^{149}$ Christian Doppler Laboratory for Allergy Research, Division of Immunopathology, Department of Pathophysiology and Allergy Research, Center for Pathophysiology, Infectiology and Immunology, Medical University of Vienna, Vienna, Austria; ${ }^{150}$ Université Paris 13, PRES Sorbonne-Paris-Cité and Assistance publique-Hôpitaux de Paris, Avicenne Hospital, Bobigny, France; ${ }^{151}$ University Hospital of Mont-Godinne, Catholic University of Louvain, Yvoir, Belgium; ${ }^{152}$ Department of Primary and Community Care, Radboud University Nijmegen Medical Centre, HB Nijmegen, The Netherlands; ${ }^{153} \mathrm{CNR}$ Institutes of Biomedicine and Molecular Immunology (IBIM), Palermo, and of Clinical Physiology (IFC), Pisa, Italy; ${ }^{154}$ Yong Loo Lin School of Medicine, National University of Singapore, Singapore, Singapore; ${ }^{155}$ Sachs' Children's Hospital, and Institute of Environmental Medicine, Karolinska Institutet, Stockholm, Sweden; ${ }^{156}$ School of Pharmacy, University of North Carolina, N.C., USA; ${ }^{157}$ Division of Immunology, Department of Dermatology, Allergy and Infectious Diseases (DIAID), Medical University of Vienna, Vienna, Austria; ${ }^{158}$ Department of Pulmonology, Celal Bayar University School of Medicine, Manisa, Turkey; ${ }^{159}$ The Allergy and Asthma Institute, Islamabad, Pakistan; ${ }^{160}$ Department of Paediatrics and Child Health, and School of Child and Adolescent Health, Red Cross Children's Hospital, University of Cape Town, Cape Town, South Africa; - ${ }^{161}$ University Clinic of Respiratory and Allergic Diseases, Golnik, Slovenia; ${ }^{162}$ Guangzhou Institute of Respiratory Diseases and State Key Laboratory of Respiratory Diseases, Guangzhou Medical College, Guangzhou, China; ${ }^{163}$ Secretary General of the Global Allergy and Asthma European Network (GA ${ }^{2}$ LEN), Network of Excellence, Charité - Universitätsmedizin Berlin, Berlin, Germany 


\section{Severity, Control, Response to Treatment and Risk in Asthma}

The stratification and grading of asthma severity includes several components (table 2). The most useful concept of asthma severity is based on the intensity of the treatment required to obtain control [26].

\section{Control}

The level of asthma control incorporates current clinical control and exacerbations over the past 6-12 months [26]. The measurement of current asthma control may be assessed by individual outcome measures such as daily or nocturnal symptoms, symptoms linked to activities or exercise, monitoring of peak flow or pulmonary function, as-needed use of relievers, and exacerbations. Used individually, these measures cannot accurately assess asthma control. A composite measure reflecting all key endpoints is more relevant [30] and has been used in guidelines [23, 31] (table 3).

Several scores for the control of asthma have been validated and translated into many languages in adults and adolescents. Examples are:

- The Royal College of Physicians' three questions [32].

- The Juniper's Asthma Control Questionnaire (ACQ),

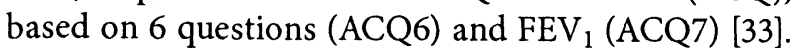
ACQ6 is more predictive than ACQ7 for asthma control [34].

- The Asthma Control Test, based on 5 questions $[35,36]$. In children, a few asthma control questionnaires have been validated $[37,38]$. None of these questionnaires appropriately assess exacerbations that are of importance in the assessment of the control of asthma and deserve further attention.

Biomarkers hold promise for capturing complementary information regarding diagnosis and risk, but need to be validated with regard to control. Biomarkers are either not readily available or completely unavailable in most practice settings [39].

Although asthma therapy is primarily aimed at controlling the disease, the control level of asthma is independent of the step of asthma treatment. Control can be achieved at any severity level and a patient under total control may still have severe disease (e.g. an oral corticosteroid-treated patient). Patients achieving control with treatment have a lower risk of exacerbation than those who are uncontrolled [39].
Table 1. Goals of the current paper

- The current document proposes a common strategy to the severity of chronic allergic (and related) diseases taken individually.

- It does not consider acute allergic reactions such as anaphylaxis.

- It does not take into account comorbidities [29].

- It is intended to be used by all stakeholders involved in the management or research of allergic (and related) diseases.

Table 2. Components contributing to asthma severity [from 23, 28]

(1) Level of control

- Current clinical control (impairment): symptoms, health status and functional limitations over previous 2-4 weeks

- Severe exacerbations over previous 6-12 months (use of oral or systemic corticosteroids)

(2) Level of current treatment prescribed

(3) Inhalation technique and compliance to treatment

(4) Responsiveness to treatment

(5) Exposure to aggravating factors

(6) Risk

\section{Response to Treatment}

Responsiveness to treatment has been demonstrated in studies assessing risk reduction during treatment. Studies at the community level show a considerable reduction of hospitalizations and deaths using appropriate management [40]. Successful studies have been carried out in low- and middle-income countries $[41,42]$ and in deprived populations [43]. The concept is therefore applicable to all populations and all countries. In the NAEPP-EPR3 guidelines [23], resistance to therapy is defined as uncontrolled asthma despite corticosteroids inhaled at high doses. For the INNOVATE trial (omalizumab), the European Medical Agency requested the assessment of asthma control in patients treated by inhaled corticosteroids and long-acting $\beta$-agonists [44].

\section{Risk}

The concept of asthma risk [23] is intended to capture:

- The likelihood of future asthma exacerbations.

- Progressive loss of pulmonary function over time (or for children, reduced lung growth).

- Risk of adverse effects from treatment, which should always be considered carefully.

These domains respond differentially to treatment. The assessment of risk domain is more difficult than the evaluation of control. 
patients, affordable. However, in many low- and middle-income countries and in some deprived areas of high-income countries, essential medicines may be available but are rarely affordable [50], although they should be in formularies. Even if medications are affordable, health professional knowledge concerning their optimal use is fragmented and requires training. Furthermore, the health system often lacks infrastructure for early diagnosis, follow-up and education as well as legislation for appropriate referral.

- Reassessment of the diagnosis of the disease: In patients who are uncontrolled despite optimal treatment, all reasonable efforts to eliminate other diagnoses must be made. Patients may suffer from a mild disease that is considered to be severe because it is underlined by another disease (e.g. wheezing in cystic fibrosis). It may be difficult to ascribe the differential severity to the allergic disease or the underlying one. On the other hand, there may be a degree of overdiagnosis which could lead to a false impression of severe disease.

- Difficult-to-treat severe disease represents a category in which partial or poor response to treatment reflects factors other than the disease alone. Issues to address in such cases include:

- Poor adherence to treatment.

- Incorrect inhalation technique.

- Adverse environmental circumstances such as passive smoke or allergen exposure.

- Psychosocial issues.

- Comorbidities which cannot be controlled.

Any or all of these factors can be very important in any chronic disease.

- Patients with treatment-dependent severe disease are those who require the highest level of recommended treatment to maintain control. This requirement for high doses of medication and multiple medications suggests a component of treatment resistance or insensitivity. Although the disease is controlled, the patients are at risk of exacerbations if treatment is inappropriately reduced or becomes unavailable.

- Patients with treatment-resistant severe disease are those who are partially or poorly controlled despite the highest recommended treatment provided according to the guidelines existing in the country (or if guidelines do not exist, the highest controller medications available in the country). This insensitivity may not be an absolute phenomenon, but varies from patient to patient and with time.

- Severity should be reassessed at regular intervals as it may change over time.

\section{Severe Allergic and Related Diseases}

\section{Allergic and Nonallergic Rhinitis (and}

Rhinoconjunctivitis)

Allergic rhinitis is an IgE-mediated reaction of the nasal mucosa. It is often associated with conjunctivitis (rhinoconjunctivitis) [11]. Nonallergic rhinitis represents a group of heterogeneous diseases in which no IgE-mediated reaction can be demonstrated [17]. Clinical needs that are not met are clear in both allergic and nonallergic rhinitis [51].

\section{Control}

Control and severity are not well delineated in rhinitis. Using the new definition, measures of the control of allergic rhinitis include symptom scores, visual analogue scales (VAS) [52], objective measures of nasal obstruction such as peak inspiratory flow measurements, acoustic rhinometry and rhinomanometry [53], a recent modification of the ARIA (Allergic Rhinitis and its Impact on Asthma) severity classification [54], or patients' reported outcomes such as quality of life $[11,55]$. More recently, a score with several items was proposed [56]. In rhinitis, it appears that a simple measure such as VAS may be sufficient to appreciate the control of the disease [57] and is particularly relevant to primary [58] and pharmacy care [59]. The level of control of allergic rhinitis is assessed independently of the treatment step $[52,60]$.

\section{Responsiveness to Treatment}

Most patients with allergic rhinitis can be controlled using guideline-based treatment. However, among patients with moderate to severe symptoms who comply with an adequate treatment according to the guidelines, up to $20 \%$ continue to be impaired by their symptoms. The Global Allergy and Asthma European Network (GA ${ }^{2}$ LEN)-ARIA-World Allergy Organisation (WAO) task force has proposed the new appellation of severe chronic upper airways disease (SCUAD) for these cases where patients' symptoms are not sufficiently controlled despite their pharmacological treatment [51, 61]. However, SCUAD applies to all nasal diseases irrespective of the allergic component. Allergic conjunctivitis is frequently associated with pollen-induced rhinitis but it is more difficult to control than rhinitis [62].

The efficacy of the treatment of nonallergic rhinitis is variable [17]. It is heterogeneous in etiologies and inconsistently benefits from treatments which are effective in allergic rhinitis $[63,64]$. 
Reassessment of the Diagnosis of the Disease

Many different conditions can mimic allergic and nonallergic rhinitis [65]. Local allergic reactions with nasal but not systemic IgE antibodies [66] may be more important than initially thought. Misdiagnosis (e.g. nasal tumors, granulomas, cerebrospinal or rhinorrhea) may lead to adverse outcomes if the patient is not appropriately reassessed and reviewed.

\section{Risk}

Allergic rhinitis impairs work $[67,68]$ and school performance $[69,70]$. Moreover, sedation may be enhanced using $\mathrm{H}_{1}$-antihistamines with sedative properties [71]. The major long-term risk of allergic and nonallergic rhinitis is the development of asthma [72].

\section{Chronic Rhinosinusitis}

Control

Control and severity are not well delineated in chronic rhinosinusitis (CRS). Using the new definition, it is proposed that an overall symptom score measured by VAS may more accurately monitor control and could be combined with disease-specific $[18,73]$ and generic health status assessment instruments [18].

\section{Responsiveness to Treatment}

Responsiveness to treatment differs between CRS without nasal polyps (CRSsNP) and in CRS with nasal polyps (CRSwNP) [74-76]. The principle of SCUAD also applies to CRS [51].

The pathophysiology of CRSsNP is poorly understood [19] and treatment options are limited to topical corticosteroids [18]. According to clinical experience and reports, sinus surgery improves symptoms in the short term in $65-90 \%$ of cases.

In CRSwNP, symptoms may be controlled by topical corticosteroid treatment in mild to moderate localized disease [77-79]. However, in severe polyposis and asthma comorbidity, repeated courses of intranasal and/or oral corticosteroids are usually insufficient in controlling symptoms. Repeated sinus surgeries may be needed with inconsistent clinical benefits [80].

Reassessment of the Diagnosis of the Disease

The differential diagnosis includes all forms of rhinitis, as well as underlying sinus diseases such as cystic fibrosis, primary ciliary dyskinesia, noninvasive fungal sinusitis, allergic fungal sinus disease and invasive forms [18]. Sinus headache needs to be differentiated from neurological, ocular or facial pains. Other rare diagnoses include gran- ulomatosis with polyangiitis (Wegener's), other granuloma diseases, cocaine abuse or lymphomas. Any unilateral obstruction, pain or bleeding has to be investigated by a specialist to exclude malignancies, inverted papilloma, meningoceles and other serious conditions [81].

\section{Risk}

Very rarely, acute complications with a spread of the disease into the orbit, the meninges, the brain or frontal bone (osteomyelitis) may develop in the course of acute exacerbations of the disease. Mucoceles develop slowly as long-term complications after surgery, but can also develop spontaneously.

About $10-15 \%$ of CRSsNP and up to $45 \%$ of CRSwNP patients present or will develop comorbid asthma, which may be severe [82]. CRSwNP may also develop into a systemic disease such as aspirin-exacerbated respiratory disease [83] or Churg-Strauss syndrome [84]. Allergic fungal sinus disease may be accompanied by allergic bronchopulmonary aspergillosis.

Repeated courses of oral corticosteroids in patients with persistent CRS may affect bone metabolism and lead to HPA-axis dysfunction $[78,85]$.

\section{Chronic Urticaria}

Urticaria describes the spontaneous or inducible occurrence of wheals and flares often accompanied by pruritus which generally subside within hours while new lesions occur. Chronic urticaria is a group of spontaneous or inducible diseases characterized by symptom persistence or reoccurrence over 6 weeks $[21,86]$ with several clinical unmet needs [87]. Angioedema describes a deep swelling in the dermis which can be accompanied by pain and predominantly involves soft tissues, e.g. in the face (eyelids, lips) or genital area.

\section{Control}

Control and severity are not well delineated in chronic urticaria [87]. Using the new definition, control can be assessed by the daily number of wheals and by the intensity of the pruritus as assessed using the weekly urticaria activity score [88] and/or the Chronic Urticaria Quality of Life Questionnaire $[89,90]$. Patient diaries and healthrelated quality of life instruments can be used.

\section{Responsiveness to Treatment}

In chronic urticaria, symptomatic treatment is the rule since causal treatment is rarely effective $[22,87]$. Chronic urticaria can be fully controlled in a minority of patients by following the guideline-recommended 
spontaneously improves after 1-2 years. Children with early onset, a filagrin mutation and a food allergy (mainly peanut) have almost a $100 \%$ risk of developing allergic asthma [114]. On the other hand, about $30 \%$ of adult patients seem to develop specific IgE against selfproteins, suggesting an autoimmune form of $\mathrm{AD}$ in adulthood for which allergen avoidance is therefore meaningless [115].

Due to a strongly impaired innate immunity response of the epidermal barrier in $\mathrm{AD}$, these patients have a high risk of developing superinfections with bacteria such as Staphylococcus aureus, fungi such as Malassezia sympodialis or herpes simplex virus, or causing eczema herpeticum, a severe complication of AD [116, 117]. The increased permeability of the skin associated with chronic inflammation may also favor sensitization to haptens, causing increasing rates of allergic contact dermatitis [118].

\section{Application to Children}

\section{Severe Problematic Asthma}

Severe problematic asthma is probably as common in children as in adults, with approximately $4-5 \%$ of children with asthma being affected [119]. Phenotypes of severe problematic asthma differ in children and in adults $[120,121]$. A proposal with a 4 -step procedure for the diagnosis and assessment of severe problematic asthma in childhood has recently been published [122]. The steps include: (a) a full diagnostic work-up that may exclude other chronic lung diseases which may mimic severe asthma; (b) a multidisciplinary assessment to identify factors of importance including comorbidities; (c) an assessment of the pattern of inflammation, and (d) a documentation of the level of corticosteroid responsiveness.

\section{Allergic Rhinoconjunctivitis and Chronic}

Rhinosinusitis

For children, there is an increasing awareness that rhinitis may start in very early childhood, but definitions and control measures are largely lacking. Treatment challenges are frequently more pronounced in children, with sparse documentation of pharmacological intervention in severe disease, which is often part of complex atopic disease presentation.

It is difficult to diagnose allergic rhinitis/conjunctivitis in preschool children. Furthermore, children of this age have frequent infections of the upper airways and management is challenging due to a lack of guidelines, comorbidities and a lack of objective parameters to guide diagnosis.

There are specific problems in childhood/adolescence such as general symptoms of malaise occurring during important school and university examinations in the spring pollen season [123]. In children, it may be difficult to distinguish between persistent nonallergic rhinitis and rhinitis associated with recurrent respiratory tract infections. It is important to rule out cystic fibrosis or primary ciliary dyskinesias in patients suspected of chronic rhinosinusitis.

\section{Importance of a Uniform Approach}

\section{Subphenotyping Severe/Uncontrolled Diseases}

Allergic diseases represent complex multidimensional diseases with marked heterogeneity depending on environmental factors and socio-economic determinants. Tools to phenotype individual disease subtypes are now being developed in order to characterize the various patterns of triggers that induce symptoms, different clinical presentations of the disease and different inflammatory markers. This is the case for asthma (US Severe Asthma Research Program [124, 125], U-BIOPRED [45, 126]) and allergic disease onset (MeDALL, Mechanisms of the Development of Allergy, an FP7 European Union project [49]), but more research is needed to identify allergic disease subphenotypes or endophenotypes [127] based on severity.

Phenotyping subtypes can be used to characterize and predict disease severity, progression and response to treatment, and may help identify unique targets for treatment [26]. Heterogeneity also exists within each dimension of the disease (e.g. eosinophils and asthma severity) $[128,129]$, across diseases (e.g. eosinophils in asthma and COPD) and in relation to comorbidities [130, 131]. Phenotypes may also change over time.

Phenotype heterogeneity may reflect a priori defined hypotheses or lead to the generation of novel hypotheses through multiple logistic regression $[130,131]$, cluster analysis $[125,132]$ or free-scale networks. However, a uniform definition applied worldwide is needed, which may allow detailed subphenotyping of severe allergic diseases to be approached [28].

\section{Clinical Practice}

A uniform definition provides a framework to decide who needs targeting for treatment or improved treatment [28]. It will help in the delivery of appropriate health care through better organization for diagnosis 
ly around the world. Research must be planned to evaluate the phenotypes of 'severe' allergic (and related) diseases from different countries.

\section{Development of Novel Therapies}

For treatment-resistant severe allergic (and related) diseases, more detailed cellular and molecular phenotyping is needed to identify new targets for the development of novel therapies and to improve current therapies in a cost-effective manner. Ultimately, novel therapies studied in clinical trials should help define the pathogenesis of the diseases and determine the importance of the treatment in large patient populations or in subpopulations of patients based on the concept of distinct phenotypes.

\section{Conclusions}

It is likely that a uniform definition of severe allergic diseases will help in a better understanding of phenotypes, but there is a need for a validation process of the proposed definition for severe chronic allergic diseases across different populations and countries with different incomes, age groups and disease phenotypes.

\section{Acknowledgments}

This paper is part of MeDALL WP2 and was completed during a meeting in CREAL, Barcelona (June 29-30, 2011), and the French-Speaking Respiratory Forum (Espace Francophone de Pneumologie, Société de Pneumologie de Langue Française, Nice, July 8-10, 2011) in collaboration with the WHO Collaborating Center for Asthma and Rhinitis (Montpellier).

\section{References}

1 Johansson SG, Bieber T, Dahl R, Friedmann PS, Lanier BQ, Lockey RF, et al: Revised nomenclature for allergy for global use: report of the Nomenclature Review Committee of the World Allergy Organization, October 2003. J Allergy Clin Immunol 2004;113:832836.

2 Bousquet J, Anto JM, Bachert C, Bousquet PJ, Colombo P, Crameri R, et al: Factors responsible for differences between asymptomatic subjects and patients presenting an IgE sensitization to allergens. A GA2LEN project. Allergy 2006;61:671-680.

3 Svanes C, Sunyer J, Plana E, Dharmage S, Heinrich J, Jarvis D, et al: Early life origins of chronic obstructive pulmonary disease. Thorax 2010;65:14-20.

4 Sampson HA, Munoz-Furlong A, Campbell RL, Adkinson NF Jr, Bock SA, Branum A, et al: Second symposium on the definition and management of anaphylaxis: summary report - Second National Institute of Allergy and Infectious Disease/Food Allergy and Anaphylaxis Network symposium. J Allergy Clin Immunol 2006;117:391-397.

5 Demoly P, Pichler W, Pirmohamed M, Romano A: Important questions in Allergy. 1. Drug allergy/hypersensitivity. Allergy 2008; 63:616-619.

6 Sicherer SH, Sampson HA: Food allergy. J Allergy Clin Immunol 2010;125(suppl 2):S116-S125.

7 Bilo BM, Rueff F, Mosbech H, Bonifazi F, Oude-Elberink JN: Diagnosis of hymenoptera venom allergy. Allergy 2005;60:13391349.
8 Zuraw BL: Clinical practice: hereditary angioedema. N Engl J Med 2008;359:10271036.

9 Krause K, Zuberbier T, Maurer M: Modern approaches to the diagnosis and treatment of cold contact urticaria. Curr Allergy Asthma Rep 2010;10:243-249.

10 Roujeau JC: Clinical heterogeneity of drug hypersensitivity. Toxicology 2005;209:123129.

11 Bousquet J, Khaltaev N, Cruz AA, Denburg J, Fokkens WJ, Togias A, et al: Allergic Rhinitis and its Impact on Asthma (ARIA) 2008 update (in collaboration with the World Health Organization, GA(2)LEN and AllerGen). Allergy 2008;63(suppl 86):8-160.

12 Bousquet J, Khaltaev N: Global Surveillance, Prevention and Control of Chronic Respiratory Diseases: A Comprehensive Approach. World Health Organization, 2007, p 148.

13 Bieber T: Atopic dermatitis. N Engl J Med 2008;358:1483-1494.

14 Pearce N, Pekkanen J, Beasley R: How much asthma is really attributable to atopy? Tho$\operatorname{rax} 1999 ; 54: 268-272$.

15 Weinmayr G, Forastiere F, Weiland SK, Rzehak P, Abramidze T, Annesi-Maesano I, et al: International variation in prevalence of rhinitis and its relationship with sensitisation to perennial and seasonal allergens. Eur Respir J 2008;32:1250-1261.

16 Bousquet PJ, Leynaert B, Neukirch F, Sunyer J, Janson CM, Anto J, et al: Geographical distribution of atopic rhinitis in the European Community Respiratory Health Survey I. Allergy 2008;63:1301-1309.
17 Bousquet J, Fokkens W, Burney P, Durham SR, Bachert C, Akdis CA, et al: Important research questions in allergy and related diseases: nonallergic rhinitis: a GA2LEN paper. Allergy 2008;63:842-853.

18 Fokkens W, Lund V, Mullol J: EP3OS. European position paper on rhinosinusitis and nasal polyps. Rhinology 2007;45(suppl 20):1-139.

19 Bachert C, Van Bruaene N, Toskala E, Zhang $\mathrm{N}$, Olze $\mathrm{H}$, Scadding $\mathrm{G}$, et al: Important research questions in allergy and related diseases: 3-chronic rhinosinusitis and nasal polyposis - a GALEN study. Allergy 2009; 64:520-533.

20 Hastan D, Fokkens WJ, Bachert C, Newson RB, Bislimovska J, Bockelbrink A, et al: Chronic rhinosinusitis in Europe - an underestimated disease. A GA ${ }^{2}$ LEN study. Allergy 2011;66:1216-1223.

21. Zuberbier $T$, Asero R, Bindslev-Jensen $C$, Walter Canonica G, Church MK, GimenezArnau A, et al: EAACI/GA(2)LEN/EDF/ WAO guideline: definition; classification and diagnosis of urticaria. Allergy 2009;64: 1417-1426.

22 Zuberbier T, Asero R, Bindslev-Jensen C, Walter Canonica G, Church MK, GimenezArnau AM, et al: EAACI/GA(2)LEN/EDF/ WAO guideline: management of urticaria. Allergy 2009;64:1427-1443.

23 Expert panel report 3: Guidelines for the diagnosis and management of asthma. National Asthma Education and Prevention Program. National Heart, Lung and Blood Institute. US Department of Health and Human Services, 2007; p 440. 
62 Bousquet J, Lund VJ, Van Cauwenberge P, Bremard-Oury C, Mounedji N, Stevens MT, et al: Implementation of guidelines for seasonal allergic rhinitis: a randomized controlled trial. Allergy 2003;58:733-741.

63 Webb DR, Meltzer EO, Finn AF Jr, Rickard $\mathrm{KA}$, Pepsin PJ, Westlund R, et al: Intranasal fluticasone propionate is effective for perennial nonallergic rhinitis with or without eosinophilia. Ann Allergy Asthma Immunol 2002;88:385-390.

64 Greiner AN, Meltzer EO: Pharmacologic rationale for treating allergic and nonallergic rhinitis. J Allergy Clin Immunol 2006;118: 985-998.

65 Bousquet J, Van Cauwenberge P, Khaltaev N: Allergic rhinitis and its impact on asthma. J Allergy Clin Immunol 2001;108(suppl 5):S147-S334.

66 Rondon C, Romero JJ, Lopez S, Antunez C, Martin-Casanez E, Torres MJ, et al: Local IgE production and positive nasal provocation test in patients with persistent nonallergic rhinitis. J Allergy Clin Immunol 2007; 119:899-905.

67 Dykewicz MS, Fineman S: Executive summary of joint task force practice parameters on diagnosis and management of rhinitis. Ann Allergy Asthma Immunol 1998;81: 463-468.

68 Bousquet J, Neukirch F, Bousquet PJ, Gehano P, Klossek JM, Le Gal M, et al: Severity and impairment of allergic rhinitis in patients consulting in primary care. J Allergy Clin Immunol 2006;117:158-162.

69 Blaiss MS: Allergic rhinitis and impairment issues in schoolchildren: a consensus report. Curr Med Res Opin 2004;20:1937-1952.

70 Simons FE: Learning impairment and allergic rhinitis. Allergy Asthma Proc 1996;17: 185-189.

71 Church MK, Maurer M, Simons FE, Bindslev-Jensen C, van Cauwenberge P, Bousquet J, et al: Risk of first-generation $\mathrm{H}(1)$-antihistamines: a GA(2)LEN position paper. Allergy 2010;65:459-466.

72 Shaaban R, Zureik M, Soussan D, Neukirch C, Heinrich J, Sunyer I, et al: Rhinitis and onset of asthma: a longitudinal populationbased study. Lancet 2008;372:1049-1057.

73 Lim M, Lew-Gor S, Darby Y, Brookes N Scadding G, Lund VI: The relationship between subjective assessment instruments in chronic rhinosinusitis. Rhinology 2007;45: 144-147.

74 Van Zele T, Claeys S, Gevaert P, Van Maele G, Holtappels G, Van Cauwenberge P, et al: Differentiation of chronic sinus diseases by measurement of inflammatory mediators. Allergy 2006;61:1280-1289.

75 Zhang N, Van Zele T, Perez-Novo C, Van Bruaene N, Holtappels G, Deruyck N, et al: Different types of T-effector cells orchestrate mucosal inflammation in chronic sinus disease. J Allergy Clin Immunol 2008;122:961968.
76 Van Bruaene N, Derycke L, Perez-Novo CA, Gevaert P, Holtappels G, De Ruyck N, et al: TGF-beta signaling and collagen deposition in chronic rhinosinusitis. J Allergy Clin Immunol 2009; 124:253-259.

77 Stjarne P, Blomgren K, Caye-Thomasen P Salo S, Soderstrom T: The efficacy and safety of once-daily mometasone furoate nasa spray in nasal polyposis: a randomized, double-blind, placebo-controlled study. Acta Otolaryngol 2006;126:606-612.

78 Mullol J, Obando A, Pujols L, Alobid I: Corticosteroid treatment in chronic rhinosinusitis: the possibilities and the limits. Immunol Allergy Clin North Am 2009;29:657-668.

79 Vaidyanathan S, Barnes M, Williamson P Hopkinson P, Donnan PT, Lipworth B: Treatment of chronic rhinosinusitis with nasal polyposis with oral steroids followed by topical steroids: a randomized trial. Ann Intern Med 2011;154:293-302.

80 Vento SI, Ertama LO, Hytonen ML, Wolff $\mathrm{CH}$, Malmberg $\mathrm{CH}$ : Nasal polyposis: clinical course during 20 years. Ann Allergy Asthma Immunol 2000;85:209-214.

81 Alobid I, Guilemany JM, Mullol J: Nasa manifestations of systemic illnesses. Curr Allergy Asthma Rep 2004;4:208-216.

82 Bachert C, Zhang N, Holtappels G, De Lobe $L$, van Cauwenberge $P$, Liu S, et al: Presence of IL- 5 protein and IgE antibodies to staphylococcal enterotoxins in nasal polyps is as sociated with comorbid asthma. J Allergy Clin Immunol 2010;126:962-968.

83 Kowalski ML, Makowska JS, Blanca $M$, Bavbek S, Bochenek G, Bousquet J, et al: $\mathrm{Hy}-$ persensitivity to nonsteroidal anti-inflammatory drugs (NSAIDs) - classification, diagnosis and management: review of the EAACI/ENDA(\#) and GA2LEN/HANNA* Allergy 2011;66:818-829.

84 Fuchs HA, Tanner SB: Granulomatous dis orders of the nose and paranasal sinuses. Curr Opin Otolaryngol Head Neck Surg 2009;17:23-27.

85 Bonfils P, Halimi P, Malinvaud D: Adrena suppression and osteoporosis after treatment of nasal polyposis. Acta Otolaryngol 2006;126:1195-1200.

86 Kaplan AP, Greaves M: Pathogenesis of chronic urticaria. Clin Exp Allergy 2009;39: 777-787.

87 Maurer M, Weller K, Bindslev-Jensen C, Gimenez-Arnau A, Bousquet $P$, Bousquet J, et al: Unmet clinical needs in chronic spontaneous urticaria. A GA ${ }^{2} \mathrm{LEN}$ task force re port. Allergy 2011;66:317-330.

88 Mathias SD, Dreskin SC, Kaplan A, Saini SS, Spector S, Rosen KE: Development of a daily diary for patients with chronic idiopathic urticaria. Ann Allergy Asthma Immunol 2010; 105:142-148.

89 Mlynek A, Zalewska-Janowska A, Martus P Staubach P, Zuberbier T, Maurer M: How to assess disease activity in patients with chronic urticaria? Allergy 2008;63:777-780.
90 Baiardini I, Braido F, Brandi S, Canonica GW: Allergic diseases and their impact on quality of life. Ann Allergy Asthma Immunol 2006;97:419-430.

91 Kropfl L, Maurer M, Zuberbier T: Treatment strategies in urticaria. Expert Opin Pharmacother 2010;11:1445-1450.

92 Neven B, Prieur AM, Quartier dit Maire P: Cryopyrinopathies: update on pathogenesis and treatment. Nat Clin Pract Rheumatol 2008;4:481-489.

93 Soubrier M: Schnitzler syndrome. Joint Bone Spine 2008;75:263-266.

94 Valent $\mathrm{P}$, Arock M, Bischoff SC, Buhring HJ, Brockow K, Escribano L, et al: The European Competence Network on Mastocytosis (ECNM). Wien Klin Wochensch 2004;116:647-651.

95 Magerl M, Borzova E, Gimenez-Arnau A Grattan CE, Lawlor F, Mathelier-Fusade P, et al: The definition and diagnostic testing of physical and cholinergic urticarias EAACI/GA2LEN/EDF/UNEV consensus panel recommendations. Allergy 2009;64: 1715-1721.

96 Dreskin SC, Andrews KY: The thyroid and urticaria. Curr Opin Allergy Clin Immunol 2005;5:408-412.

97 Willemsen R, Roseeuw D, Vanderlinden J Alexithymia and dermatology: the state of the art. Int J Dermatol 2008;47:903-910.

98 Severity scoring of atopic dermatitis: the SCORAD index. Consensus Report of the European Task Force on Atopic Dermatitis. Dermatology 1993;186:23-31.

99 Hanifin JM, Thurston M, Omoto M, Cherill R, Tofte SI, Graeber M: The eczema area and severity index (EASI): assessment of reliability in atopic dermatitis. EASI Evaluator Group. Exp Dermatol 2001;10:11-18.

100 Schmitt J, Langan S, Williams HC: What are the best outcome measurements for atopic eczema? A systematic review. J Allergy Clin Immunol 2007;120:1389-1398.

101 Rajka G, Langeland T: Grading of the severity of atopic dermatitis. Acta Derm Venereol Suppl (Stockh) 1989;144:13-14

102 Stalder JF, Barbarot S, Wollenberg A, Holm EA, De Raeve L, Seidenari S, et al: Patientoriented SCORAD (PO-SCORAD): a new self-assessment scale in atopic dermatitis validated in Europe. Allergy 2011;66:11141121.

103 van Velsen SG, Knol MJ, Haeck IM, Bruijnzeel-Koomen CA, Pasmans SG: The Selfadministered Eczema Area and Severity Index in children with moderate to severe atopic dermatitis: better estimation of $\mathrm{AD}$ body surface area than severity. Pediatr Dermatol 2010;27:470-475.

104 Alanne S, Nermes M, Soderlund R, Laitinen K: Quality of life in infants with atopic dermatitis and healthy infants: a follow-up from birth to 24 months. Acta Paediat 2011;100:65-70. 